\title{
Designing for the Gap: The space between the OPV and the Frigate
}

Andy C. Kimber ${ }^{1}$

\begin{abstract}
One of the enduring struggles for the warship designer has been the design of the affordable warship; a ship that offers useful military capability at a fixed and ideally lower price than a pure frigate or destroyer type. BMT has been investigating this design space, through the creation of a patrol ship design called the "Venator 110", using a variety of tools to measure performance rapidly. A capability modelling tool has been developed to rapidly compare how different designs achieve military roles and how modular systems may be used to enhance a platform. Investigations have also focused on exploring methods of achieving pragmatic enhancements to survivability. These draw on the company's experience in developing naval and auxiliary ships which use a mix of naval and commercial equipment and practises to "tailor" survivability. Finally, design solutions that offer maximum flexibility have been incorporated within the design to explore their practicality.
\end{abstract}

Key words: Capability, Survivability, Modularity, Affordability.

\section{Resumen}

Una de las luchas duraderas para el diseñador de buques de Guerra ha sido el diseño asequible de una embarcación de estas características; un buque que ofrezca capacidad militar útil en un ajustado e idealmente más bajo precio que una fragata o una fragata tipo destructor. BMT ha estado investigando este espacio de diseño, a través de la creación del diseño de un patrullero llamado "Venator 110", usando una variedad de herramientas para medir desempeño rápidamente. Una herramienta de modelado de capacidades ha sido desarrollada para comparar rápidamente cómo diferentes diseños logran los roles militares y cómo los sistemas modulares pueden ser usados para mejorar una plataforma. También las investigaciones han sido enfocadas en la exploración de métodos de mejora para la supervivencia. Estos se basan en la experiencia de la compañía en el desarrollo de embarcaciones navales y auxiliares, las cuales usan una mezcla de equipos navales y comerciales, y prácticas para "ajustar" la supervivencia. Finalmente, las soluciones de diseño que ofrecen una máxima flexibilidad han sido incorporadas dentro del diseño para explorar su practicidad.

Palabras claves: Capacidad, supervivencia, modularidad y asequibilidad.

Date Received: December 24th, 2014 - Fecha de recepción: 24 de diciembre de 2014

Date Accepted: February 19th, 2015 - Fecha de aceptación: 19 de febrero de 2015

${ }^{1}$ BMT Defence Services Ltd.. United Kingdom. Email: akimber@bmtdsl.co.uk 


\section{Introduction}

One of the enduring struggles for the warship designer has been the design of the affordable warship - a ship that offers useful military capability but at a fixed and ideally much lower price than a true frigate or destroyer type. Historically many navies have adopted this type of vessel, for example the Royal Navy's Type 14 or Type 21 frigates. However, this type of vessel seems to have become less fashionable since the later part of the last century, with many navies choosing to dispose of these vessels although in favour of smaller numbers of high end warships.

Looking forward, with many navies focused on delivering maritime security rather than posturing, and continued world economic constraints, ship designers and builders are again turning to the affordable patrol vessel as an alternative to the frigate. BMT has been investigating this design space, through the creation of a patrol ship / patrol frigate design called the "Venator 110". As part of this project paper, BMT has developed a capability modelling process to compare how different designs achieve a defined set of military roles and how modular systems may be used to enhance a platform.

Within this paper, this work will be summarised, including a description of the capability assessment tool, methods of achieving pragmatic enhancements to survivability and the impacts of designing warships for flexibility and modular systems.

\section{The Affordability versus Capability Argument}

The key to affordable design is to understand what the true requirements are, in what environment they are to be conducted, and to prevent requirements creep occurring through more capability being added than strictly necessary. The designer needs to keep a close eye on the design being spiralled upwards in the enthusiasm to procure the best possible solution; but he must also be open to the opportunity to achieve extra value where cost in not significantly affected.

It is also true that the "design space" is not uniform and designs do not necessarily grow in proportion to requirements. Rather, it consists of cliff edges and plateaus where the designer can find themselves "on the wrong side" of a step change or where additional capability can be added for modest cost because of the solution adopted. This non-linear characteristic of the ship design process is explored further in Reference [1]. Such a process may not be considered appropriate in all situations and as Reference [1] suggests there is no single process able to capture all ship designs.

This implies that requirements definition and design development are parallel activities, each being traded towards the goal of an affordable solution. For a warship, there are a range of expectations of capability and often a difficulty to pin down the exact capability need and therein conduct a robust trade; for example if a ship is to be flexible, to what ends? The wide range of

Fig. 1. BMT Venator 110 - Patrol Ship (left) and Venator 90 Reconfigurable Minor Combatant (Right)
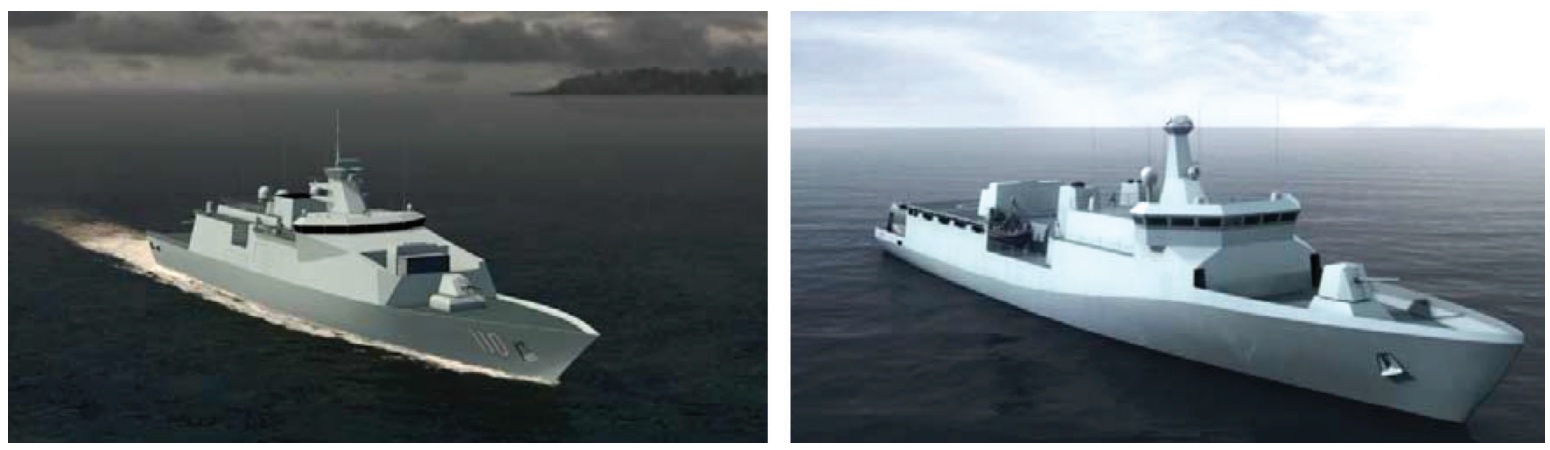
interpretations is illustrated at Reference [2]. Hence, for the Venator 110 concept the team set out to consider the following:

What, in a defined framework, is the vessel expected to do?

- What coherent steps in military fit should be considered?

- What level of survivability is consistent with the above?

- What is the range of flexibility expected and how can this be achieved in a design which is still affordable and buildable?

For small navy combatants, the typical vessel types are expressed as frigates, corvettes or OPV's. The former is typically an ocean going complex combatant and the latter a simple off-shore vessel. The Author would contend that a corvette represents a complex but short endurance vessel, whilst a patrol ship would offer longer endurance but be a simpler platform ${ }^{1}$. Fig. 2 illustrates this visually. However, these terms do not represent clear boundaries, although when applying in the context of military tasking and threats they are also not necessarily a continuum; there may be gaps where no useful capability exists. The variation of cost will in general occur in a diagonal across the diagram as shown; from bottom left to top right represents increasing cost (or fewer platforms for a budget) whilst top left to bottom right represents a line of common cost (or class size) but represents a different sort of delivered capability (trading size / flexibility for warfighting effect / survivability).

For the purposes of the capability model described in this paper, the problem has been addressed by adopting and then tailoring the latest UK Maritime Doctrine, Reference [3], which clearly and concisely identifies a range of Military Tasks. The approach taken in the development of the Venator 110 Patrol Ship was to set the requirements against the Maritime Security Roles, whilst being able to flex to achieve the International Engagement Role (not

1 In developing the Venator 110 concept, the term "Patrol Ship" has been used to refer to a ship with similar roles to an OPV but with a blue water or global reach; the term "Patrol Frigate" is used for a more capable version of the same platform, but still less capable than a tradition frigate. requiring concurrent operations and allowing for mission specific fits) and to deliver the maximum Warfighting Role possible from the platform without increasing size, complexity and platform cost (Fig. 3). With this level of understanding, it was also possible to set survivability objectives, including identifying and recording likely threats.

Fig. 2. Relative Performance for Combatant Types.
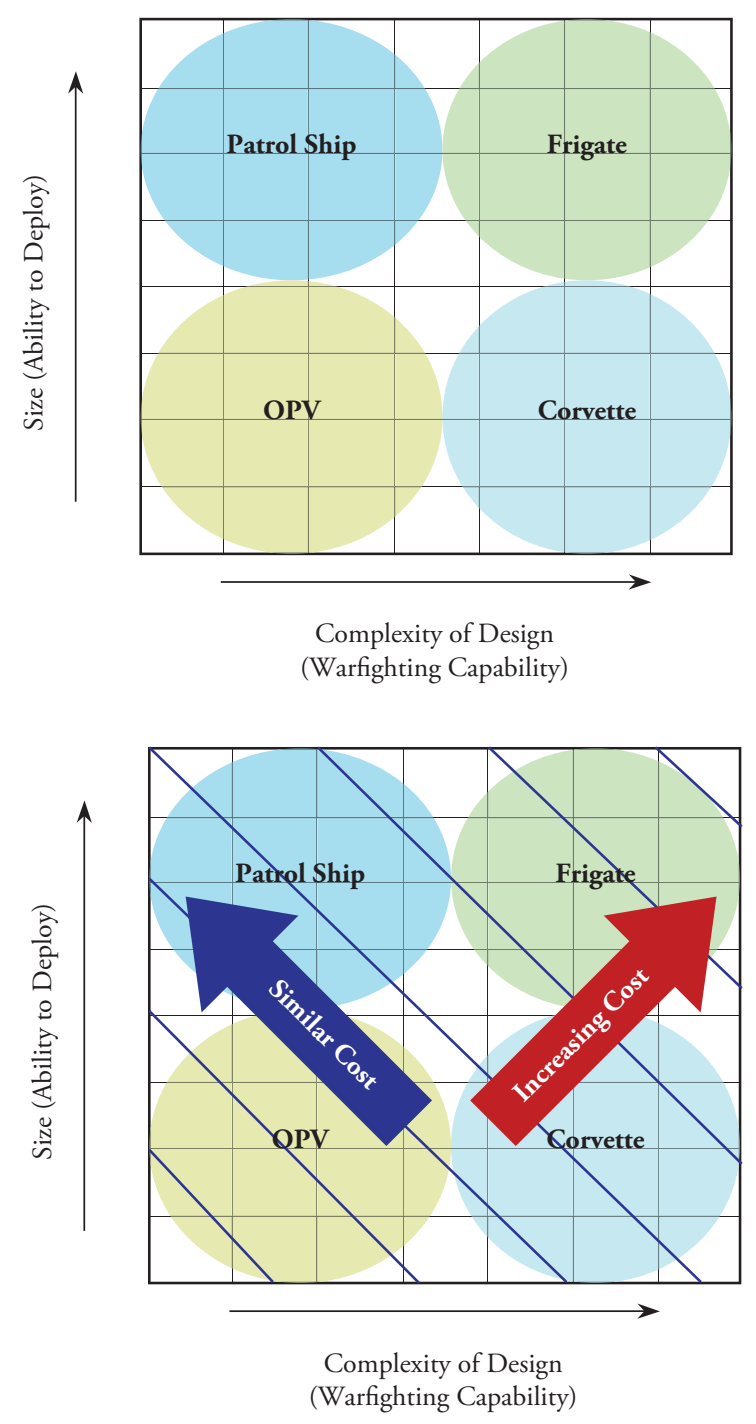

\section{Using Capability Modelling as a Design Tool}

A key enabler to trading cost and capability is the ability to "measure" the capability delivered by a design. It is important that such measurements can 
Fig. 3. Patrol Ship Roles.

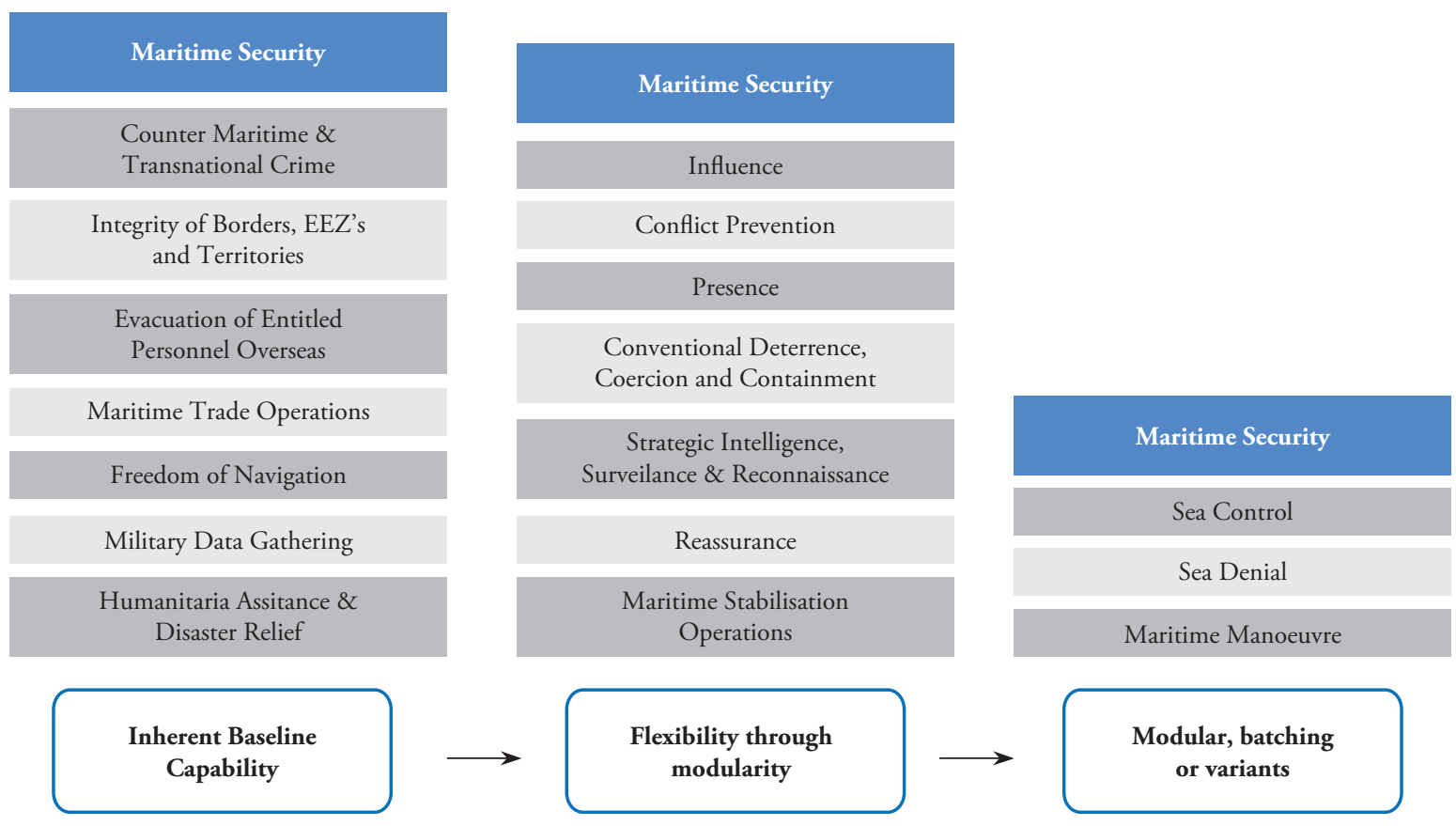

be traced to the original capability requirements; in this respect the model needs to reflect not only the performance of an individual weapon or sensor system but how each contributes to the roles the ship will perform. The model also needs to be rapid and straight forward to interpret, as complex models involving scenario modelling often take too long to produce results for the design to test the "what if?" questions throughout the design's concept development.

In the design development of BMT's Venator 110, a parallel research task was conducted to create and explore the use of a capability modelling tool. The objective of this tool, undergoing continuous development by BMT, is to provide a method which allows the rapid comparison of the capability delivered by design alternatives. The key aspect here is to undertake the comparison in terms of delivered capability rather than performance or systems selected. The tool used is based on a relational database, which provides a means to create a path that traces from the systems provided within the design to the overall capability delivered. Key to this is the recognition that this is a many to many relationship; capability is delivered by combinations of systems (even multi-layered in some cases) whilst a system may contribute to a range of capabilities.

Hence, a capability assessment tool has been developed that allows the mapping of platform capability against a variety of comparators, including Doctrine and Key User Requirements. The objective is to provide a comprehensive and easily understood picture of how a platform's physical design combined with technical system selection is able to meet key national operational requirements, or otherwise. This methodology allows comparison of the overall capability against the chosen requirements to enable platform comparison. The comparison process can be used in a variety of ways to assess system choices, the implications of specific design changes, or the ability of a platform with chosen capability to meet national requirements.

The capability assessment tool has been developed to enable a clear mapping to be carried out between the demand and supply functions for maritime platforms and the relationships between these are shown at Fig. 4. This tool can be used to assess and understand the capability decisions associated with maritime platform design. The assessment is 
tailored to suit the specific requirements of each platform type under consideration. This means that the platform comparisons are conducted on a like for like capability basis.

Fig. 4 shows the basic structure of the capability tool. The demand side starts with Doctrine, moving to subsidiary requirements. These requirements within the capability tool were previously developed from British Maritime Doctrine and have produced a detailed structure, consisting in excess of 1,800 comprehensive capability taxonomy statements that cover the maritime capability domain. These requirements are tempered and changed where necessary to reflect the requirements of the particular nation for which the analysis is performed. These requirements are weighted based on their importance in fulfilling the overarching Doctrine. Metrics are defined against the requirements, which represent measurable performance parameters to be achieved.

The supply side of the tool starts at the platform level, moving through a system or group of equipments to an individual item of equipment or platform characteristic. A number of different types

Fig. 4. Capability Tool Basic Structure.

of equipment or characteristics contribute to fulfil the requirement. For example under the Armada de la República de Colombia policy statement, Reference[4], 'Consolidation of Territorial Control' the requirement to 'neutralise land targets; Mobile; Infantry' is included. The requirement for 'search, detect and track surface targets', 'identify surface targets' and 'determine intent of surface targets' are also included (amongst others) to capture all of the contributory factors necessary to fulfil the policy.

The metrics assigned to the demand requirements can then be directly linked to the metrics supplied by the selected equipment. The example shown in Fig. 4 (76mm Medium Calibre Gun System) is but one performance metric between one item of equipment and one requirement. Outside of this example shown, the $76 \mathrm{~mm}$ capability is measured by a number of metrics beyond a simple range analysis. Prior to the final capability diagrams being generated there are a significant number of such weighted performance metrics considered within the tool, to provide a comprehensive view of capability.

The output for each platform variant is plotted as a solid line on the Radar Plot to allow direct capability comparison on a like for like basis, and a representative version of this plot can be seen at the base of Fig. 4. Each axis should be considered separately; a discrete value when comparing platform types. For example, a platform score cannot be directly compared against a score on a different axis for the same platform, but can be compared with another score on the same axis for a different platform, facilitating a direct comparison between platform options.

\section{Survivability}

Many ship designers will recognise survivability as a cost driver and many studies have been conducted to identify "affordable" survivability. A fundamental part of providing cost effective survivability is to understand the threats and to ensure that the design presents a balanced solution, such that the correct measures are included to protect against the threats in the environment associated with the tasks that the ship is designed to conduct.

Survivability is a multi-layered capability that enshrines the operational doctrine, equipment and system specification, material design and the operational procedures adopted. Creating a design solution that successfully achieves the right level of survivability requires consideration of all these aspects in a balanced and coherent way. Having a clear understanding of the requirement for survivability is critical for developing both a robust and cost effective approach. There are two elements to defining the approach to survivability:

- The level of capability to be maintained, which defines the aspects of the ship which require protection;

- The threat level, which determines the level of protection to be provided.

As a simplification, an approach taken for a frigate could be to define the worst case threats likely to be encountered and to define the set of capabilities to be maintained (for example, propulsion and key combat systems). This defines the set of equipments and systems requiring protection, the remaining non-critical systems needing no protection. In the case of an OPV, survivability over and above safety considerations under normal operating conditions is paid little attention as these are not considered warships. Often the design is based on the application of (commercial) classification society rule sets to ensure crew and vessels safety in a nonthreatening environment. Neither approach offers significant cost scaling, rather a binary decision to provide protection or not.

However, as OPV like vessels are increasingly seen as force multipliers to supplement warships in limited threat environments and indeed warships are more cost constrained and capability traded, there is a need to consider a more layered approach to ship vulnerability. In defining the threat and capability to be maintained, there may be a case for a scaled approach in which the capability maintained is graduated against increasing threats. This becomes a risk based consideration. 
Prescribing proven (military) equipment and systems to achieve vulnerability protection across many systems reduces the risk of vessel loss but adds cost. As the decision is taken to relax the extent of system capabilities retained post damage, or adopting good practise guidance with more commercial approaches rather than specifying tested and proven military equipment, then risk is increased but cost reduced. Ultimately the correct balance point becomes where affordability is achieved with acceptable risk levels for loss of capability during the perceived range of missions.

As a minimum, the vessel needs to offer safety and protection to the crew for all scenarios. In principle, a starting assumption may be that an OPV-like warship may spend much of its time in a maritime security environment in which there is no or limited military threat. The threat may be characterised as man-portable, low technology weapons of short range (e.g. hand weapons, machine guns or rockets). In this situation, the platform is likely to be operating as an independent unit and therefore minimum loss of capability will be preferable. When the same platform is operating at a higher threat level, it will be in operations beyond maritime security and therefore may be assumed as a supporting unit to other more capable units. As a supporting unit, the level of capability to be maintained could be much reduced, perhaps to float / crew safety and potentially only a limited move capability.

This approach allows both 'capability to be maintained', and 'threat' to be considered and traded for each system to achieve a cost effective policy against the appropriate combinations, as demonstrated in Table 1. It should be noted this is not the same as the disposable warship concept, which suggests warships are produced cheaply such that more vessels balance the greater risk of loss in high threat environments (as envisaged for example by the "Streetfighter" concept, Reference [5]). Here, the argument is that warfighting is primarily delivered by the vessels designed for the purpose whilst a vessel such as the patrol frigate is a supporting asset and therefore the loss of its capability should not represent a significant risk to force level mission success.
Table 1. Proposed Levels of Survivability for Patrol Ship

\begin{tabular}{|c|c|c|}
\hline & $\begin{array}{c}\text { Low Threat } \\
\text { Environment }\end{array}$ & $\begin{array}{l}\text { Higher Threat } \\
\text { Environment }\end{array}$ \\
\hline Float & Retain full capability & $\begin{array}{l}\text { Maintain Float for } \\
\text { safety of crew (e.g. } \\
\text { to allow ordered } \\
\text { abandonment if } \\
\text { necessary) }\end{array}$ \\
\hline Move & $\begin{array}{l}\text { Retain full capability } \\
\text { or partial capability } \\
\text { (e.g. } 50 \% \text { power and } \\
\text { propulsion) }\end{array}$ & $\begin{array}{l}\text { Either no move or } \\
\text { limited propulsion to } \\
\text { maintain steerage / safe } \\
\text { navigation }\end{array}$ \\
\hline Fight & $\begin{array}{l}\text { Retain full capability } \\
\text { or self-defence as } \\
\text { minimum }\end{array}$ & $\begin{array}{l}\text { No capability } \\
\text { maintained }\end{array}$ \\
\hline
\end{tabular}

Another useful approach to explore is the adoption of classification society rules that offer appropriate levels of vulnerability protection. Although not intended to achieve warship survivability objectives, the use of classification society rules offer a degree of certainty (as they are articulated rules that will not change during design and construction). It would allow use of some commercial practises and equipment suppliers, and many shipyards are familiar with their application and approval against class rules. The wider application of classification society rules and the advantages are discussed in Reference [6].

Whilst adoption of class rules may not mitigate all potential risks, combining classification society rules with project specific guidance to tailor the class notations can result in acceptable performance whilst retaining many "commercial" practises, effectively as "owner's requirements" would for commercial vessels. This guidance may take the form of prohibiting specific materials in the design of systems or specification of equipments, such as those of a brittle nature (e.g. cast iron) or which are likely to result in dangerous fragments (e.g. glass).

The design of the structure may adopt commercial practises and structural profile sections ${ }^{2}$. Enhanced performance may be achieved under weapon damage through careful attention to

2 Such as Off-set Bulb Profiles (OBP) instead of traditional "T" sections. 
structural details, avoiding those known to have poor resilience to the effect of weapon damage. Again this can be achieved through project specific structural policies and guidance (i.e. avoiding stress concentrations, sharp corners, the use of gussets to spread loads).

Many classification societies have redundant power and propulsion notations (such as the LR PMSR or DNV RPS notations). Adoption of a redundant power and propulsion notation for a patrol ship would ensure that the potential failure leading to loss of the move function (and hence loss of mission) could be reduced to a negligible level. As some of the notations also specify separation of power and propulsion into independent machinery rooms, some degree of protection is afforded to loss of a machinery room due to flood or fire as a result of either accidental or weapon damage.

An example of how this philosophy is applied is the arrangement of the power and propulsion solution. The following approaches could be applied to a ship to offer increasing levels of protection from attack:

- Single engine room and generator room but redundant equipment to class society notation, offering redundancy to equipment failure but no redundancy for compartment loss;

- Separate engine rooms with power and propulsion arranged in each to class society notation, offering redundancy if one compartment suffers flood or fire but with no redundancy if the adjoining bulkhead is breached, e.g. by fragments;

- Separated engine rooms with a protected bulkhead between as an owners enhancement to a class society notation, offering redundancy if one compartment suffers flood or fire and with limited capability to maintain redundancy against fragments and small arms;

- Separated engine rooms with at least one compartment separation as typically adopted for a frigate, offering redundancy against flood, fire and weapons damage to a level consistent with the separation achieved.

The separation of engines rooms offers survivability improvements as illustrated in Reference [7].
However, such arrangements have a significant impact on the design and become a size driver as the engine rooms are forced further towards the ends of the hull and the uptake arrangements require separate funnels. It is therefore important to understand if the improvement in survivability is actually justified by the capability need.

For the Venator 110, given the survivability intent described in Table 1, providing redundancy for power and propulsion as a result of fire or flood in one engine room would offer significant operational advantage, as it would provide for a graceful loss of capability in the event of an accident. Some degree of protection for the separating bulkhead would also mitigate fragment or small arms causing loss of adjacent engines rooms. However, the design impact of separating the engine rooms by another space would outweigh the advantage as it would only enhance vessel survivability against larger threats, which was not a stated design objective. In the smaller Venator 90 design, the separation of the engines is not practical and in this case the solution reverts to the next level, offering redundancy in equipment but not in the arrangement. However, an auxiliary drive may prove attractive in offering a limited level of redundancy.

\section{Modularity as an Enabler}

The incorporation of "modularity", or perhaps more correctly "flexibility" into designs seeks to address a number of objectives as described below (Reference [8] also provides further discussion on modularity):

- Reduce acquisition and through life costs by allowing one ship class to address multiple roles;

- Reduce acquisition and through life costs by allowing one ship to perform the role of several legacy platforms;

- Reduce acquisition costs by simplifying the integration interface between ship and equipment;

- Reduce through life costs by allowing future capability / technology insertion; 
However, these perceived advantages must be traded against the cost of incorporating modularity, which includes the cost of developing and purchasing modules; the increased platform size to accommodate modules; and the cost of storing and maintaining modules when not deployed on vessels.

In fact, modularity can be achieved at a variety of levels with differing impacts on platform design and cost, for example from Reference [9]:

- Construction modularity - use of modules to simplify construction interfaces and integration;

- Configuration modularity (e.g. $\mathrm{MEKO}^{\oplus}$-class ships) - use of modularity to allow different configurations to be adopted within one design;

- Mission modularity (e.g. Stanflex series of vessels) - the use of modules to allow one ship to change its capability between missions;

- Battle (network) modularity - the use of modularity to allow one ship to reconfigure elements to adapt capability during a mission.

Table 2 attempts to show the relationship between these objectives and the approach taken to modularity. A further variation in the theme of modularity that is emerging in more recent designs is how modularity is incorporated into the design. Two approaches have been adopted:

- Flexible space able to accommodate a range of different "modules", equipment and other items (for example, as applied to the USN LCS, UK Type 26 and Danish Absalom Class);

- Specific module spaces allocated around the ship for installing different "types" of module (for example the Danish Stanflex).

The former approach is being increasingly adopted in modern designs as it would appear to offer the most flexible Mission Modularity solution. A large "garage" area, often capable of embarking multiple ISO TEU containers gives the ultimate flexibility; if the capability can be accommodated within then the ship may carry it. However, such "garages" have significant design impacts. Some of these are discussed at Reference [10] and they are generally associated with the large volume required (containers are not a space efficient approach to providing capability) and the subsequent impact on ship size and structural configuration. These impacts are significant enough to warrant the designer to consider if this is really the most cost effective means of delivering the required flexibility.

Table 2. Potential Cost Savings for different approached to Modularity.

\begin{tabular}{|c|c|c|c|c|}
\hline & $\begin{array}{c}\text { Construction } \\
\text { modularity }\end{array}$ & $\begin{array}{c}\text { Configuration } \\
\text { modularity }\end{array}$ & Mission modularity & $\begin{array}{c}\text { Battle (network) } \\
\text { modularity }\end{array}$ \\
\hline $\begin{array}{c}\text { Reduce } \\
\text { Individual } \\
\text { Ship } \\
\text { Acquisition } \\
\text { Cost } \\
\end{array}$ & Yes & $\begin{array}{l}\text { Yes (reduces design and } \\
\text { non-recurring costs across } \\
\text { classes) }\end{array}$ & $\begin{array}{l}\text { No, likely to increase } \\
\text { individual ship cost as } \\
\text { greater size required }\end{array}$ & $\begin{array}{l}\text { No, likely to increase } \\
\text { individual ship cost due } \\
\text { to greater complexity }\end{array}$ \\
\hline $\begin{array}{c}\text { Reduce } \\
\text { Number of } \\
\text { Classes }\end{array}$ & No & $\begin{array}{l}\text { Yes, one class may } \\
\text { perform multiple legacy } \\
\text { class roles }\end{array}$ & $\begin{array}{l}\text { Yes, one class may } \\
\text { perform multiple legacy } \\
\text { class roles }\end{array}$ & $\begin{array}{l}\text { Yes, one class may } \\
\text { perform multiple legacy } \\
\text { class roles }\end{array}$ \\
\hline $\begin{array}{c}\text { Reduce } \\
\text { Number of } \\
\text { Ships }\end{array}$ & No & $\begin{array}{l}\text { No, as reconfiguration } \\
\text { is still generally fixed for } \\
\text { each ship }\end{array}$ & $\begin{array}{l}\text { Yes, provided that the } \\
\text { roles are not concurrent }\end{array}$ & $\begin{array}{l}\text { Yes, provided the roles } \\
\text { can be reconfigured } \\
\text { at sea }\end{array}$ \\
\hline $\begin{array}{c}\text { Reduce } \\
\text { Through Life } \\
\text { Modification } \\
\text { Costs }\end{array}$ & Likely to be limited & $\begin{array}{l}\text { Yes, as equipments may } \\
\text { still be switched }\end{array}$ & $\begin{array}{l}\text { Yes, as equipments may } \\
\text { still be switched }\end{array}$ & $\begin{array}{l}\text { Limited as this level } \\
\text { does not suggest } \\
\text { significant equipment } \\
\text { change }\end{array}$ \\
\hline
\end{tabular}


Table 3. Characteristics for Modular Capabilities.

\begin{tabular}{lll}
\hline \multicolumn{1}{c}{ Modular Capability } & & \multicolumn{1}{c}{ Characteristic } \\
\cline { 1 - 2 } $\begin{array}{ll}\text { Enhance warfighting capability - additional launchers, } \\
\text { for control of off-board vehicles, enhanced electronic } \\
\text { warfare or increased planning facilities) }\end{array}$ & & $\begin{array}{l}\text { Requires upper deck space and sufficient structural } \\
\text { clearance for munitions }\end{array}$ \\
\cline { 1 - 2 } $\begin{array}{ll}\text { Additional off-board vehicles } \\
\text { located for ease of access from other "command" spaces }\end{array}$ \\
\cline { 1 - 2 } $\begin{array}{l}\text { Additional stores - for increased endurance or } \\
\text { humanitarian operations }\end{array}$ & $\begin{array}{l}\text { Enclosed space but external to hotel environment to } \\
\text { offer protection to vehicles, with access to flight deck } \\
\text { or overboard to deploy }\end{array}$ \\
\hline
\end{tabular}

When conducting the development of the Venator 110 concept, the adopted approach was to consider how a number of "modules" could be provided which require different characteristics. Based on the defined roles (as illustrated in Fig. 3) it was concluded that the capabilities could be provided in a modular form, with corresponding characteristics as illustrated in Table 3.

This approach results in a vessel with a number of defined flexible areas, each capable of embarking one or two modules, as an alternative to a single large garage area. This requires a compromise in terms of overall flexibility (now limited by the size of each flexible space) but allows the spaces to be more integrated within the design. The final design solution adopted incorporates three flexible spaces, as illustrated in Fig. 5:

1. Forward, open to the topside and suitable for containers or weapon modules;

2. Midships, suitable for containers which could plug into the aft end of the forward superstructure which contains the command spaces;

3. Aft and adjacent to the hangar, to allow for an additional boat, unmanned vehicles or additional stores.

Fig. 5. Venator 110 Flexible Spaces (as described above:

Mid-ships [2], top right; Forward [1], bottom right; Aft [3], left).

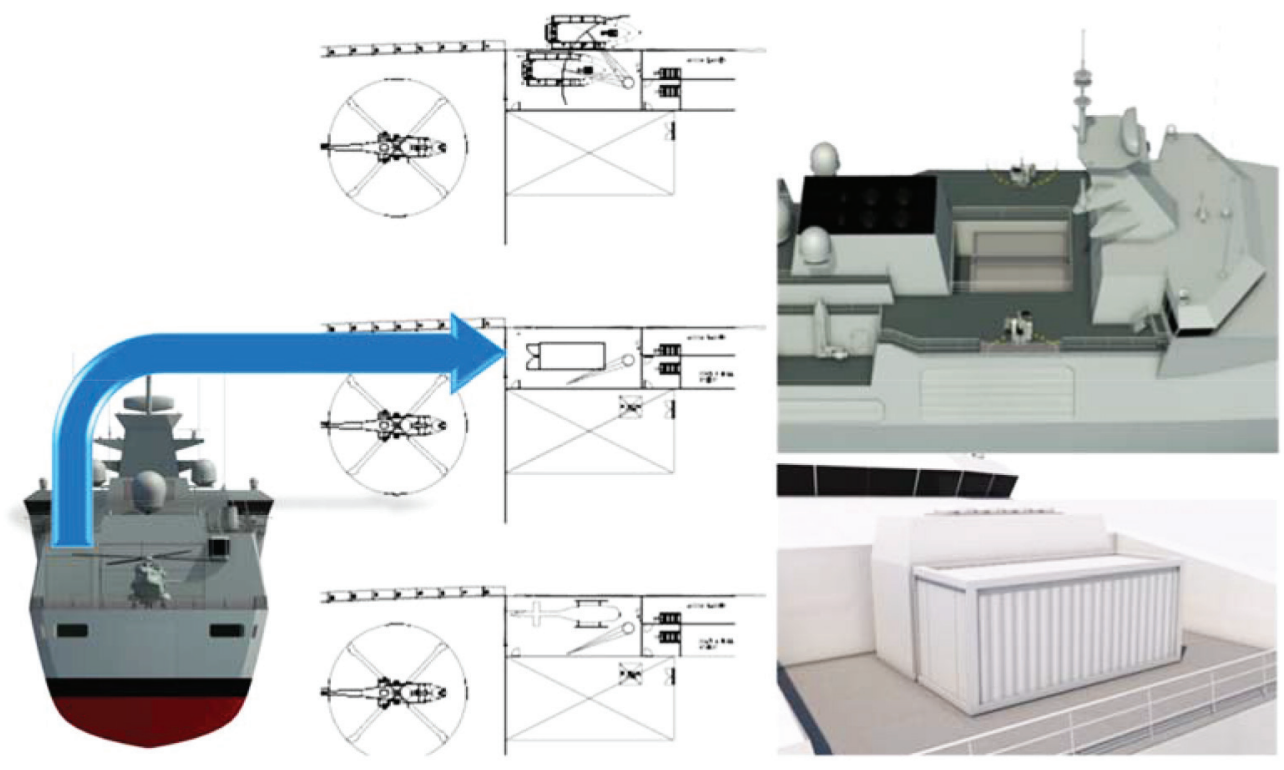




\section{Conclusions}

The design of small surface combatants have in recent years led to a range of different vessel configurations, varying not only in size but in capability and flexibility. This has led to more vessels being designed outside of the traditional frigate or OPV design envelopes. Matching the target vessel cost, achieved capability and ability to survive in the intended threat environment will lead to the increased use of capability and survivability modelling to ensure that the platform designs are capable of delivering against the navy's requirements. This modelling is becoming necessary as the vessel designs fall outside of the prescribed norms and standards for the traditional vessel types and confidence in the designs robustness requires greater testing at early design stages.

In addition to the cost and capability debate, the increased need for flexibility and the perceived use of modularity to achieve cost savings will lead to complex debates over the correct design solution. Modularity is used to express a range of solutions to different objectives and the designer will need to truly understand the objective to ensure the correct selection of a modular solution.

\section{Acknowledgements}

The Author wishes to thank his colleagues at BMT Defence Services who have contributed to this work. In particular, James Johnson and Jeremy Atkins for supplying key elements.

\section{References}

[1]: ANDREWS, D., PERCIVAL, V., PAWLING, R. Just How Valid is the Ship Design Spiral Given the Existence of Cliffs and Plateaux?, 11th International Marine Design Conference, Glasgow UK, 2012.
[2]: SELF, A. G. Multi-Purpose Patrol Vessels, Naval Forces Volume 1, 2011.

[3]: Joint Doctrine Publication 0-10, UK Ministry of Defence, August 2011.

[4]: Republic of Colombia Ministry of National Defense: 'Policy for the Consolidation of Democratic Security (PCDS)', 2007.

[5]: http://www.globalsecurity.org/military/ systems/ship/streetfighter.htm

[6]: JAMES, P., REDWOOD, N. Use of Classification and Standards to Develop an Affordable Assurance Process, Journal of Naval Engineering Volume 45(3), 2010.

[7]: JONES, A., KIMBER, A. Balancing Survivability, Operability and Cost for a Corvette Design, RINA Warship, Bath UK, 2012.

[8]: HOOD, M. Sea Change? Navies make progress in delivering modular capability, Jane's Navy International, October 2014.

[9]: KIMBER, A., GILES, W. Minor Warship Roles - How technology is leading to a new vessel type, International Maritime Conference, Sydney Australia, 2008.

[10]: KIMBER, A. Boat Launch and Recovery - A Key Enabling Technology For Flexible Warships, International Maritime Conference, Sydney Australia, 2012. 